\title{
Austrianvineyards.com - the world's first nationwide information and presentation system of all wine estates
}

\author{
Karel Kriz ${ }^{\mathrm{a}, *}$, Alexander Pucher ${ }^{\mathrm{b}}$ \\ a University of Vienna, karel.kriz@univie.ac.at \\ ${ }^{b}$ University of Vienna, alexander.pucher@univie.ac.at \\ * Corresponding author
}

\begin{abstract}
:
The origin of wine is of crucial importance in the wine industry. It is an essential part of quality and is generally closely associated with the terroir of a wine. The smaller/specific the origin, the higher the attributed quality. Austria is the first country to summarise all its wine origins from the national level down to the vineyard level in a uniform way and make them available.

Austrianvineyards.com is a project that is conceptually designed and developed by the University of Vienna, Department of Geography and Regional Research in cooperation with the plan+land agency. As part of an applied research and development project commissioned by the Austrian Wine Marketing Board (ÖWM), the data on all Austrian wine estates were standardised and then cartographically visualised.

The project has a high scientific development component. In the sense of a scientifically qualitative and sustainable implementation of the project goals, research focal points were defined within the framework of the project. These included topics of efficient data management of wine-relevant (geo) information, development of adapted cartographic visualisation methods as well as concepts for user-oriented communication and presentation of the contents.

The implementation should do justice to the "image of excellence" of the Austrian wine industry and be considered "state of the art" worldwide. Austrianvineyards.com is the first platform to offer digital (geo) information on nationwide vineyards based on legal cadastral data.

Austrianvineyards.com builds on the three pillars of geo-design, geo-standardisation and geo-communication, aiming at an intuitive and comparable presentation through user-optimised and aesthetically pleasing map representations in the field of UI and UX design. In addition to the digital format, new printed vineyard maps of all Austrian wine-growing regions were cartographically designed and implemented.
\end{abstract}

Keywords: Vineyard maps, Atlas, Thematic mapping, webmapping

\section{Introduction}

The origin of a wine is of crucial importance in the wine industry. It is an essential part of its quality and is generally closely associated with the terroir of a wine. The smaller/specific the origin, the higher the attributed quality. In its strategy of origin marketing, the Austrian Wine Marketing Board (ÖWM 2010) has been focusing on the marketing of Austrian quality wine for years. A cartographic representation of all Austrian wine areas is intended to support this intention.

\subsection{Background}

The motivation of the project "Digital information and presentation system of all Austrian wine estates conception, development and implementation" was the digital representation and presentation of all Austrian wine estates including the factors relevant to these single vineyards, often referred to as "Ried".

The Austrian Wine Marketing Board launched the project for the uniform digital recording and presentation of all wine origins in Austria in 2018. The University of Vienna,
Department of Geography and Regional Research and the engineering firm plan+land joined together as project partners. With their scientific expertise, complemented by the technical knowledge of the Austrian Wine Marketing Board, the project does justice to the high quality aspirations of the Austrian wine industry.

The implementation should focus on the "image of excellence" of the Austrian wine industry and be considered "state of the art" worldwide (Kriz, 2019). With this project, the Austrian Wine Marketing Board aims to be the first generic wine marketing organisation to offer digital (geo) information on its vineyards based on legal cadastral data on a nationwide level.

The presentation of the vineyards in Austria is to be made freely available to the respective user in a clear form by means of a comprehensive digital database that combines data from a wide range of sources and for a wide range of requirements.

\subsection{Challenges}

The exact definition of the vineyards was launched by the Austrian Winegrowers' Association many years ago and is 
under the responsibility of the local winegrowers' associations. This process took several years. The newly defined vineyards were digitised by the local GIS-offices of the federal provinces and only then taken over by the project team. The particular challenge was to find a consistent form of representation for the whole project area.

The different sizes within the levels of origin posed a major challenge in the data visualization. Areas do strongly vary in its size, e.g. Großlage Kahlenberg with 22 hectares compared to Großlage Retzer Land with 7959 hectares.

Furthermore, regional differences do exist. The Ried prescriptions were only available in the traditional winegrowing provinces of Lower Austria, Burgenland., Styria. and Vienna. Moreover, Ried definitions are interpreted differently per province. In Burgenland, wine-growing estates are more generously defined and can also include larger forest areas, whereas other provinces exclude these non-wine-relevant areas.

\subsection{Implementation issues}

The project has a high development component and thus a scientific character. In the sense of a scientifically qualitative and sustainable implementation of the project goals, research focal points following the aspects of Kriz (2013) were necessary within the framework of the project. These included topics of efficient data management of wine-relevant (geo) information, development of adapted cartographic visualisation methods as well as concepts for user-oriented communication and presentation of the contents.

Building on a coherent database structure, the creation of vineyard maps (online and analogue) was intended. These visualisations should serve as the basic information material for the presentation of the high quality, the image as well as the special characteristics of wines from all Austrian designations of origin.

After three years of development work, the project was presented to the public in June 2021 (ÖWM, 2021a). The available results are printed vineyard maps for each winegrowing region as well as a digital online platform of all Austrian wine origins. Continued cooperation with the project partners ensures regular updates and further development of the project in the upcoming years.

\section{Base data}

All base data, used in the scope of the project were delimited on the basis of the legal regulations and resolutions of the National Wine Committee and are partly presented in a cartographic realisation for the first time. No data was collected or measured by the project partners themselves.

\subsection{Planted areas}

The representation of the planted vineyard area is based on data of the Integrated Administration and Control System of the EU (INVEKOS), implemented by AMA (Agrarmarkt Austria). Depending on the map scale, this data were generalised differently. Calculations on size, altitude, orientation and slope of certain areas refer exclusively to the planted area according to INVEKOS.

\subsection{Ried (single vineyard)}

The vineyard data, which is plot-accurate, was obtained from the geoinformation offices of the provinces of Burgenland, Lower Austria and Vienna and was further processed for the map representations. Only vineyards that are allowed to be indicated on wine bottles according to wine law are shown. Therefore, some vineyards designated in the Carnuntum wine-growing region are missing, e.g. Ried Goldberg in Wienerherberg. Furthermore, vineyards with the designation "Ortsried" and all "Weinbaufluren ohne Riednamen" in Lower Austria are not listed as separate origins.

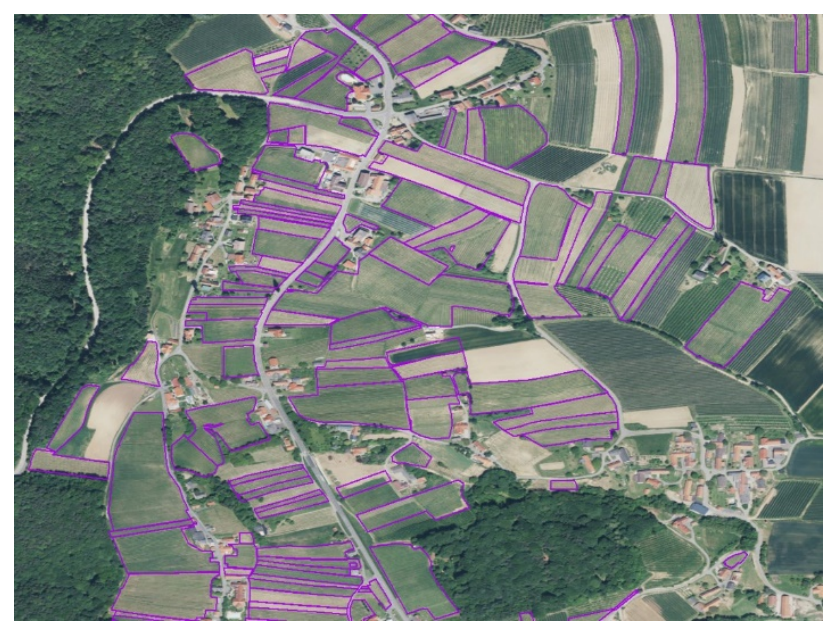

Figure 1. Single planted vineyard vector information in the area of Klöch, Steiermark.

\subsection{Climate data}

The data for generating the climate diagrams was obtained from the annual yearbook of the Austrian Central Institute for Meteorology and Geodynamics (ZAMG) with monthly resolution. This ensures that the same standardised measurement methods are used at all climate stations and that the data are comparable with each other.

\section{Data processing}

The calculation of the areas and terrain parameters (sea level, slope, aspect) was carried out through geographic information system processing, using polygons (areas) in vector format and a digital terrain model (DTM) in raster format as the data basis.

\subsection{Wine origin areas}

The polygons of the wine areas included both origins of the local GIS offices as well as field pieces from INVEKOS. On the one hand, they serve as spatial demarcation of the areas to be calculated and, on the other hand, provide attributive information. Since all field pieces are planted reed areas, only those parts of an origin are considered planted that are spatially covered by field pieces. In addition, according to INVEKOS, information 
on possible terracing is stored in each field piece. The area figures in hectares for each origin are therefore the result of adding up all the (planted) field pieces contained therein according to INVEKOS.

In total, Austrianvineyards.com includes geographic and statistical information of 27 winegrowing regions, 458 winegrowing municipalities, 56 Ortswein locations (villages wines) and 4.343 single vineyards (Rieden)

\subsection{Digital Terrain Model (DTM)}

The DTM provided the mathematical basis for all terrain calculations, as an elevation value is stored in each of its grid cells. These cells cover the whole of Austria and have a side length of $10 \mathrm{~m}$ - a raster cell of the DTM therefore covers $100 \mathrm{~m}^{2}$ on the real earth's surface. However, the terrain calculations cannot provide exact values. Especially for origins with little planted area (less than one hectare), these are therefore rough approximations.

The sea level of each provenance in metres is thus obtained from statistical calculations based on the DTM, with all field pieces per provenance being used as spatial boundaries. While the minimum height given in the online viewer corresponds to the grid cell with the smallest height value, the maximum height refers to the grid cell with the highest height value. The average height results from the arithmetic mean of the height values of all raster cells.

The slope information in degrees is calculated using the same statistics that are used to determine the elevation information. The only difference is that the elevation value is no longer stored in the raster cells but, as a result of geoprocessing, the slope angle in degrees.

The information on the aspect is also determined on the basis of the DTM, whereby all (planted) field pieces per origin are again used as the spatial delimitation. Since the grid cells no longer reflect the height value, but the aspect in degrees using geoprocessing, they are categorised into nine direction classes depending on their aspect.

The indicated cardinal direction of an origin or its contained field pieces thus results from that direction class whose raster cells have the largest number among all raster cells contained in the field pieces. The share of this most frequent cardinal direction is measured as a percentage of the sum of all direction classes.

\subsection{Meteorological data}

On a monthly basis, the long-term mean values for air temperature, precipitation and sunshine duration have been calculated. Furthermore, the data was aggregated for a reference year and the last decades on a seasonal (threemonth) and annual level.

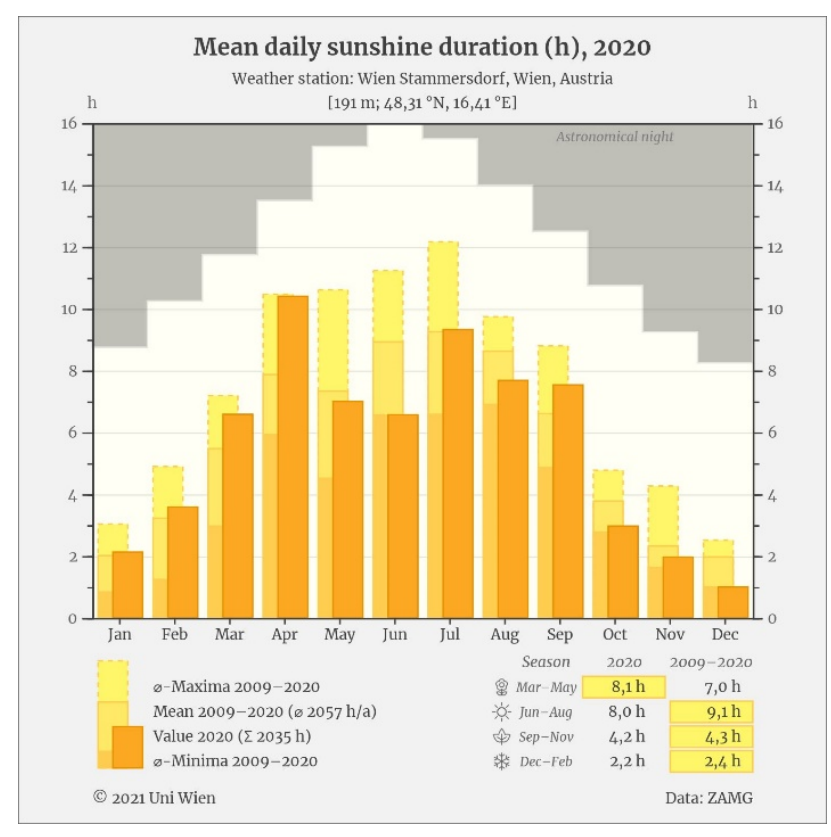

Figure 2. Mean daily sunshine duration of weather station Wien Stammersdorf.

The created diagrams visualise the measured and calculated values for air temperature, precipitation and sunshine duration, whereby the values of a reference year are compared with the values of the past decades. In addition, the legend and a seasonal table show whether higher values were measured in the reference year or the long-term average. For more information on the implementation of meteorological data within the project, refer to Wieser and Kriz (2021)

\section{Topographic maps}

In addition to the conception and implementation of a digital online platform, the creation of printed vineyard maps was an essential part of the overall project. The existing Austrian vineyard maps were thus to be updated in terms of content and cartography. Furthermore, the topographical wine maps form the basis for the online viewer and are to be used in the future as corporate identity maps in all wine-relevant areas of Austria.

\subsection{Map Data Processing}

The map contents were largely created from refined OpenStreetMap data (forest, built-up area, parks, water bodies, reeds, transport network and geographical names). In Austria, these data sources are supplemented by the more suitable, linear federal reporting water network of the Federal Environment Agency and by data from the University of Vienna. The terrain shading and the specially created contour lines were derived and refined from the digital terrain model of Austria. The foreign part was derived from SRTM data. The geometries of the administrative boundaries (state and federal province boundaries as well as origin boundaries) were obtained from the administrative boundary dataset (VGD) of the BEV. 


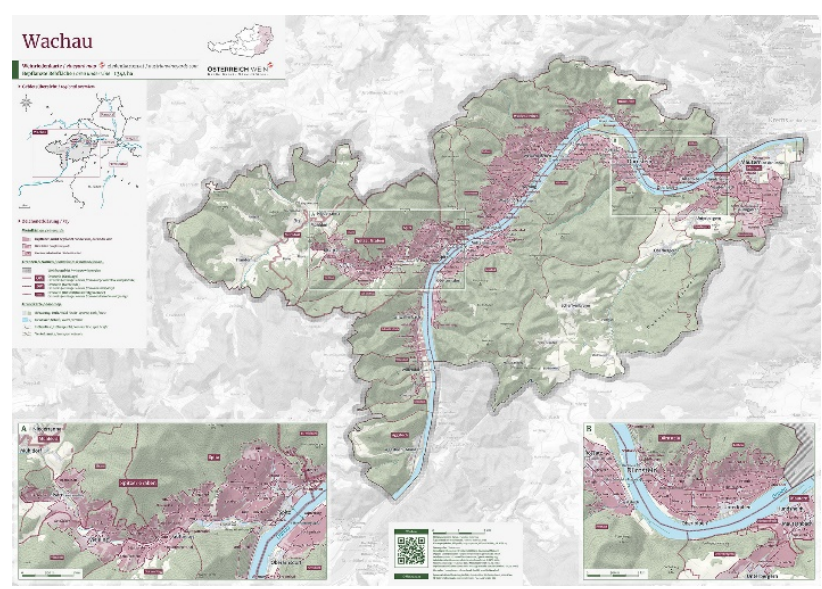

Figure 3. Analogue topographic map of the winegrowing region Wachau, Lower Austria.

\subsection{Results}

All currently available wine-relevant areas of Austria have been completely covered with single or double map sheets. The size of the individual map sheets varies from $525 \mathrm{x}$ $445.5 \mathrm{~mm}$ to $735 \times 1039.5 \mathrm{~mm}$, as all maps have a uniform scale of 1:50.000. The map sheets are available individually folded (to A4), as posters as well as folded in a complete set.

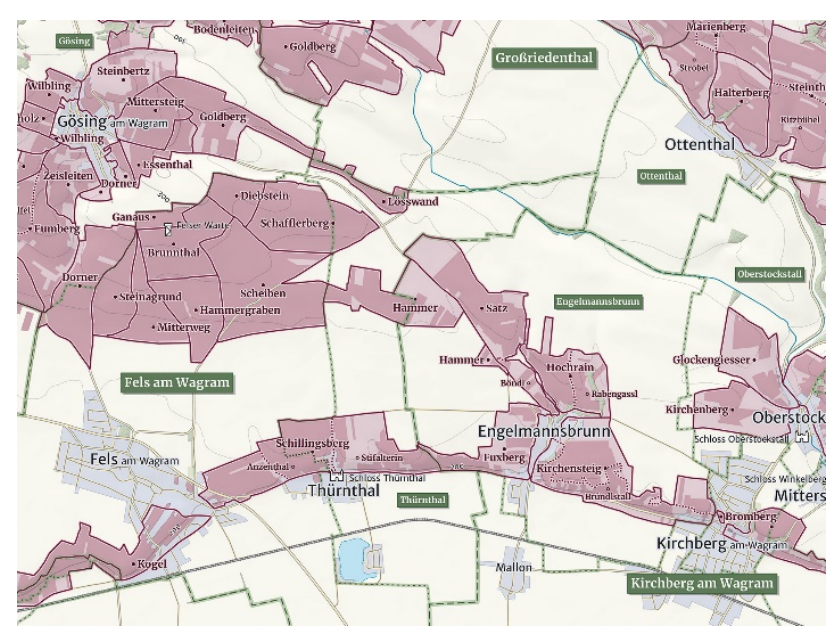

Figure 4. Detailed view of the analogue topographic map of the winegrowing region Wagram, Lower Austria.

\section{Online platform}

The online plattform focuses on customised individual maps per zoom level. The colouring and design are based on the printed vineyard maps that were developed at the same time as the online tool. The basic maps of the smaller scales (levels of origin Austria to large sites) are based on the geodata pool of the University of Vienna.

\subsection{Evaluation of best practices}

The basis for the development of the conceptional design was a comparison of existing web map applications that thematise wine (or other luxury foods). In this way, it was to be determined which operating elements are already used in established portals and how they are designed.
Through this comparison, quasi-standards were manifested. At the same time, inconsistencies in the design of other web map providers could be identified. These had to be avoided in the development of the map application of Austrianvineyards.com

The comparison was decidedly objective. Accordingly, the focus was not on an evaluation of the existing offers, but on a descriptive examination of the operating concepts that are already in use. Specifically, the focus was on the integration and implementation methods of certain elements such as information display areas, search and filter functions or layer management. Furthermore, the integration of map applications within a website itself was of importance. The interaction of these components was decisive for the usability and thus the success of the geocommunication. (Henzen, 2017)

\subsection{User experience issues}

The overall unique and innovative character of Austrianvineyards.com should be that the wealth of information is surpassed by similar web maps, for example because a large number of different layers are displayed depending on the scale. This circumstance had to be taken into account during the design process.

In the course of the conception of the online platform, three use cases were identified that cover the functional scope of the system. These were adapted to the requirements and needs of the ÖWM.

\subsubsection{Use case: "Direct access"}

The first developed use case enables the user to access Austrianvineyards.com directly via the URL or is led to it via a link on an external page. The access is undirected, thus without specific content-related questions.

\subsubsection{Use case: "Bottle label"}

In contrast to the use case above, which provides for an undirected access to the system, this case is clearly directed. It enables the user to start the online platform with the clear intention of searching for a (mostly) spatial term that can be found on a label of an Austrian wine bottle. Also direct access though technologies like QRCodes are covered by this use case.

\subsubsection{Use case: "Wikipedia"}

Building on the two use cases above, this option represents the 'silver bullet' of functional scope. It envisages, the user extending the linear directed access through interaction between information objects. Similar to the user behaviour of "Wikipedia", all spatial and thematic content in the system is interlinked. The user can move freely in this information network. For example, it is conceivable that the user starts the system by means of the use case "bottle label". As a result, he receives a precisely defined spatial and thematic view of his query. From here, he can continue his way through the system via all linked object links (e.g. superordinate or subordinate wine origin level).

\subsection{Usability issues:}

In addition, importance was attached to taking into account the basic rules of professional cartography in order to guarantee a high standard of quality. This particularly 
affects elements such as the scale bar or legend. The latter should be integrated when a map section of the web map is printed, so that the vineyard map remains a fully-fledged cartographic product in analogue form.

Ultimately, an attempt was made to design Austrianvineyards.com in such a way that, despite its comprehensive range of information on wines, it corresponds less to a technology oriented web GIS than to a user-centred web map in its operation. Accordingly, a manageable number of operating elements were to be offered without sacrificing essential functions. The desired efficient usability was always to be seen against the background of the most goal-oriented geo-communication possible. (Nivala, 2007)

In order to manage the context between functionality and ease of use, the web map application had to be designed in such a way that the operating elements are adapted to the scale displayed at any given time, so that the application remains map-centred at all times. As the web application was to be available to users with a wide range of intentions and backgrounds, it was essential that it was as intuitive as possible to use. For this reason, elements that are familiar from the compared web maps were retained in order to avoid users having to reorient themselves when calling up the vineyard map. These include components such as a search field or zoom buttons.

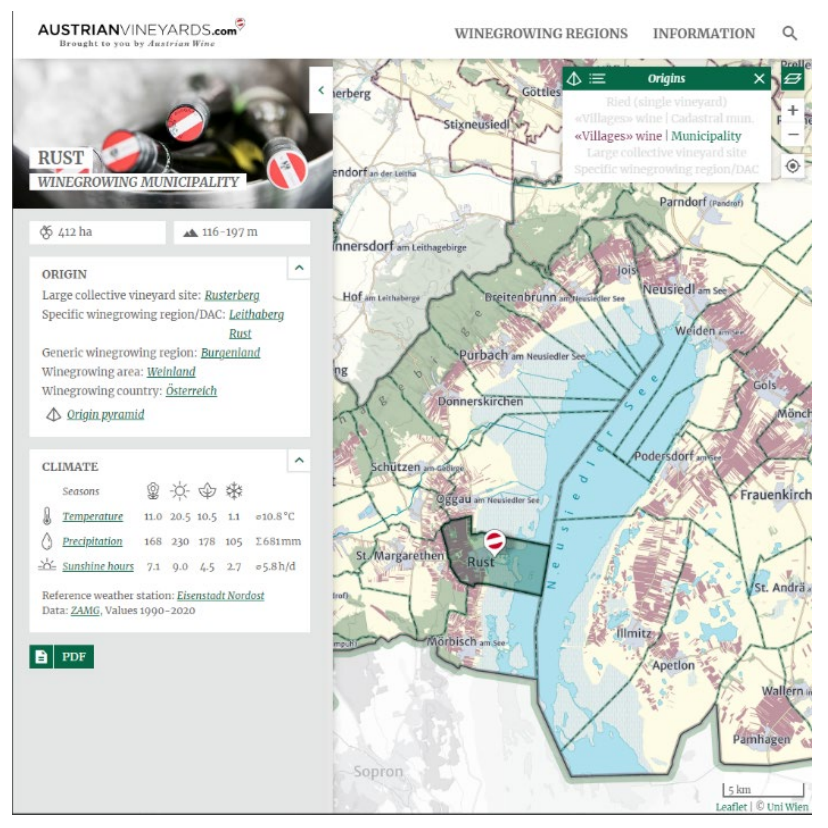

Figure 5. Austrianvineyards.com online platform

\subsection{Results}

Since its launch in 2021, a fully comprehensive digital atlas of all Austrian wine regions has been available, both technically and in terms of content. The map contents adapt to the scale and thus always guarantees optimal communication of the spatial information. In addition to the online access, all information is also available as readymade PDF documents. All areas from Austria's wine country to the smallest vineyards can be accessed as a permalink and can thus also be addressed using a QR code. Austrianvineyards.com is available in both German and English in a PC as well as mobile version.

\section{Conclusion}

Austrianvineyards.com represents a worldwide unique benchmark in the cartographic collection, processing and presentation of wine-related information of one country.

The great added value of the entire system lies in the quick findability and geographical localisation of the respective areas. Images, texts, terrain parameters and climate data on wine origins are significant enrichments for the user. Austrianvineyards.com is very much about generating emotions and telling stories: Where did the wine originate? What does it look like there? Here, geo-communication can make a significant contribution to product marketing.

The project is designed for a long term and includes annual updates of all geographical and thematic content. Content expansions are also planned. In a timely manner, information on the existing grape varieties and other legal regulations will be integrated. A link to winegrowers as well as their produced wines is considered.

\section{References}

Henzen, C., 2017. Usability-Patterns für Webanwendungen in Geodateninfrastrukturen, Dissertation, Technische Universität Dresden.

Kriz, K., 2013. Maps and Design - Influence of Depiction, Space and Aesthetics on Geo-communication. In: Kriz, K., Cartwright, W. and Kinberger, M. (Eds.), Understanding Different Geographies, Berlin, 9-24.

Kriz, K., 2019. Image of Excellence - Developing Wine Maps for Austria. In: Abstr. Int. Cartogr. Assoc., 1, 192, https://doi.org/10.5194/ica-abs-1-192-2019, 2019.

Nivala, A.-M., 2007. Usability perspectives for the design of interactive maps, Dissertation, Helsinki University of Technology.

ÖWM, 2021. Strategy for origin marketing: https://www.austrianwine.com/our-wine/strategy-fororigin-marketing. Accessed 20 August 2021.

ÖWM, 2021a. Austria's first digital wine atlas unveiled: https://www.austrianwine.com/pressmultimedia/news/news-1/article/austrias-first-digitalwine-atlas-unveiled. Accessed 20 August 2021.

Wieser, D. and Kriz, K., 2021. Climate and Vine - Representation and communication of spatio-temporal relationships in the web application AustrianVineyards.com In: Proc. Int. Cartogr. Assoc., Florence, Italy. 